\title{
INCREASE OF VOLTAGE STABILITY AND POWER LIMITS USING A STATIC VAR COMPENSTOR
}

\author{
Roberto Alves ${ }^{1}$, Miguel Montilla ${ }^{2}$ y Ernesto Mora ${ }^{2}$ \\ ${ }^{1}$ Departamento de Conversión y Transporte de Energía \\ Universidad Simón Bolívar- Caracas (Venezuela) \\ e-mail: robert@usb.ve \\ ${ }^{2}$ Escuela de Ing. Eléctrica-Departamento de Potencia \\ Universidad de Los Andes- Mérida (Venezuela) \\ e-mail: mmiguel@ing.ula.ve, morae@ing.ula.ve
}

\begin{abstract}
This paper presents an application of a Static Var Compensator (SVC). A SVC is one of the controllers based on Power Electronics and other static devices known as FACTS (Flexible AC Transmission Systems) Controllers which it could be used to increase the capacity and the flexibility of a transmission network. The system under study is an interconnected network located in the southeast region of Venezuela. The objective of our study were to increase the power flow, under the thermal capacity, through an overhead transmission lines, using a voltage stability approach. The simulations were carried out with the program ATP/EMTP (ElectroMagnetic Transients Programs), which allows the analysis of the response of the SVC and the adjustments of its control systems.
\end{abstract}

\section{Key words}

FACTS, SVC, voltage stability, power limits.

\section{Introduction}

The increasing demand of electric energy and power quality constraints has given rise to a better use of transmission, sub-transmission, and distribution electrical power systems. This paper presents a detailed study on use of Static Var Compensator (SVC) to increase the capacity and flexibility of a transmission network.

The electric power quality at the low voltage level is affected, in great dealt, by the disturbance due to switching actions or faults that happens in the power system at the middle and low voltage levels. The SVC is one of the best device that it can contribute to improve the voltages profile in the transient state and therefore, in improving the quality performance of the electric service. A SVC is one of controllers based on Power Electronics known as FACTS (Flexible AC Transmission Systems) Controllers, which can control one or more variables in a power system. The compensator studied in the present work is made up of a fixed reactance connected in series to a Thyristor-
Controlled Reactor (TRC) - based on bi-directional valves- and a fixed bank of capacitors in parallel with the combination reactance-TRC. The thyristors are turned on by a suitable control that regulates the magnitude of the current[1]. The system under study is an interconnected network located in the southeast area of Venezuela, where it is found a very important loads related to oil industry. This real and complex system, allows the study of strategies and feasible solutions for the application of the SVC. The following figure shows the systems under study:

The objectives of this study were to increase the transmitted power, under the thermal capacity, through an overhead transmission lines using a voltage stability criterion. The used approach has been the voltages stability, with the purpose of keeping the voltage magnitude on the main buses within the range of 0.8 1.2 p.u. during the transients state and after a fault located anywhere in the systems. The studied cases were:

a) A fault due to short circuit in "Guri" bus

b) Load increase in different buses of the system

\section{Static Vars Compensator (SVC)}

The FACTS are controllers based on solid states technologies, whose two main objectives are: the increase of the transmission capacity and the control of the power flow over designated transmission routes. On this way, the Controllers FACTS can be classified into four categories: Series Controllers, Shunt Controllers, Combined series-series Controllers, Combined series-shunt Controllers. The SVC fall into Shunt Controllers category and it function as a fast generators or as an fast absorber of reactive power, with the purpose so as to maintain or control specific parameters of the electric power systems (typically bus voltage). 


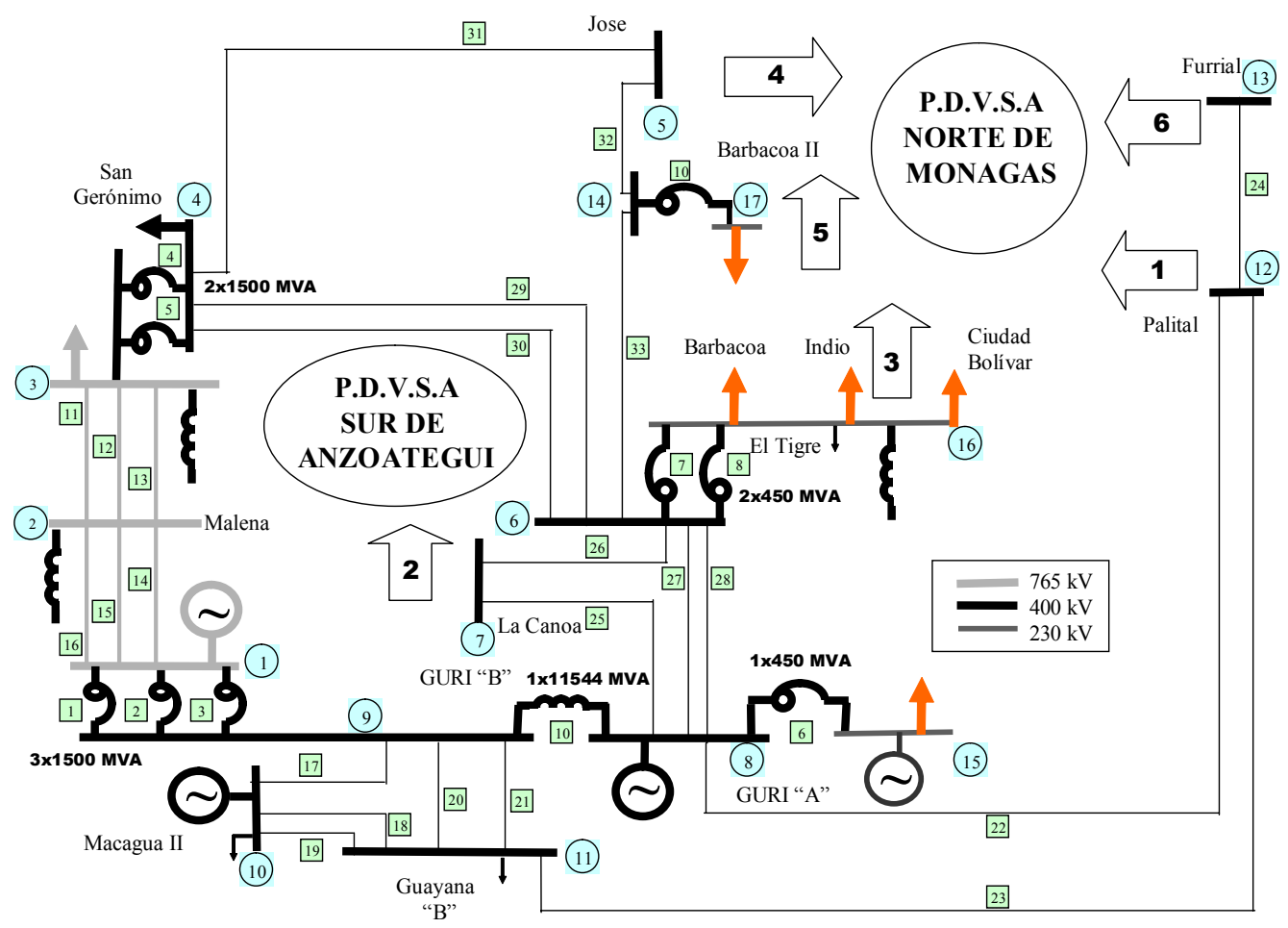

Fig.1 Model of the electric system under study (southeast region of Venezuela)

The SVC consists of a Thyristor Controlled Reactor (TCR) and a Fixed Capacitors(FC) banks. The TCR is a thyristor controlled inductor whose effectives reactance varied in a continuous manner by partial conduction control of thyristor valve. [1], [2]. The basic elements of a TCR are a reactor in series with a bidirectional thyristor switch as show in figure $\mathrm{N}^{\mathrm{o}} 2$.

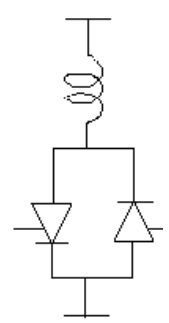

Fig. 2. Thyristor Controlled Reactor (TCR)

The thyristors conduct alternates half-cycles of supply frequency depending of the firing angle $\alpha$, which is measured from a zero crossing of voltage. Full conduction is obtained with a firing angle of $90^{\circ}$. The current is essentially reactive and sinusoidal. Partial conduction is obtained with firing angles between $90^{\circ}$ and $180^{\circ}$. Firing angle between $0^{\circ}$ and $90^{\circ}$ are not allowed as they produced asymmetrical current with a dc component. The effect of increasing the firing angle is to reduce the fundamental harmonic component of the current. This is equivalent to an increase in the inductance of the reactor, reducing its reactive power as well as its current. So far as the fundamental component of current is concerned, the thyristor-controlled reactor (TCR) is a controllable susceptance, and can therefore be applied as a static compensator[1].

Also, the conduction angle $\sigma$ can be define as a function of the firing angle $\alpha$ by:

$$
\sigma=2(\pi-\alpha)
$$

The instantaneous current in the TRC is given by:

$$
\mathrm{i}=\left\{\begin{array}{lr}
\frac{\sqrt{2} \mathrm{~V}}{\mathrm{X}_{\mathrm{L}}(\cos \alpha-\cos \omega \mathrm{t}),} & \alpha<\omega \mathrm{t}<\alpha+\sigma \\
0, & \alpha+\sigma<\omega \mathrm{t}<\alpha+\pi
\end{array}\right.
$$

where $\mathrm{V}$ is the voltage r.m.s applied the TRC and $\mathrm{XL}=\omega \mathrm{L}$ is fundamental-frequency reactance of the reactor. The fundamental component is found by Fourier analysis and is given by:

$$
\mathrm{I}_{1}=\frac{\mathrm{V}}{\mathrm{X}_{\mathrm{L}}} \frac{\sigma-\operatorname{sen} \sigma}{\pi} \quad[\mathrm{A}] \mathrm{r} . \mathrm{m} . \mathrm{s}
$$

We can write equation (3) as:

$$
\mathrm{I}_{1}=\mathrm{B}_{\mathrm{L}}(\sigma) \mathrm{V}
$$

where $\mathrm{BL}(\mathrm{s})$ is an adjustable fundamental-frequency susceptancia controlled by the conduction angle according to the following control law, 


$$
\mathrm{B}_{\mathrm{L}}(\sigma)=\frac{\sigma-\operatorname{sen} \sigma}{\pi \mathrm{X}_{\mathrm{L}}}
$$

as a function of the firing angle, $\alpha$

$$
\mathrm{B}_{\mathrm{L}}(\alpha)=\frac{2(\pi-\alpha)+\operatorname{sen} 2 \alpha}{\pi \mathrm{X}_{\mathrm{L}}}
$$

The maximum value of the variable susceptancia is $1 / \mathrm{XL}$, obtained with $\sigma=180^{\circ}\left(\alpha=90^{\circ}\right)$ and the current on the reactor is maximum. The minimum value is zero, obtained with $\sigma=0^{\circ}\left(\alpha=180^{\circ}\right)$. This control principle is called phase control[1].

\section{A. Characteristic of SVC}

Speed of response: The TRC has a control in its firing angle $\alpha$ that varies between $90^{\circ}$ and $180^{\circ}$. Its speed of response is sufficiently quickly in applications caused by rapidly fluctuating loads. On the other hand, in power system is important that the control of the TRC is stable and exact.

Independent Phase Control: The Three-Phase TRC used in the SVC, can be independently controlled the three-phase of a power system, so that it can balance any unsymmetrical three-phase load when it are presented [3].Under unbalance conditions, a TRC can generate more harmonics than under balanced conditions. For this reason, it is necessary, usually, to placed passive filter LC, using for that the same compensation capacitors. In this case, the injection of the reactive power of the SVC is due to the filters and the fixed capacitors.

Response to Overvoltage and Undervoltage: This is one of the most important characteristics of the SVC, because it compensates the voltage when conditions of very high or very low voltage are presented in the bus where the compensator is placed. In that case, it injects the reactive power necessary to restore the normal voltage magnitude.

\section{B. Thyristor Controlled Reactor with Unswitched (Fixed) Capacitor (TCR-FC)}

The SVC under study, consist of a thyristor controlled reactor (TCR) and a fixed capacitors bank (FC) as it is shown in figure No 3.

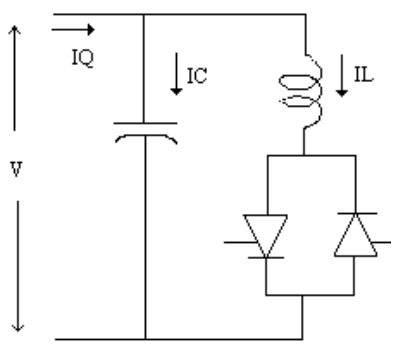

Fig. 3 Basic FC-TCR type static var compensator
The fixed capacitors bank (FC) alone supplies a part of the capacitive var required by the system, while the other part by the passive filters. The filters are placed in parallel with the fixed capacitors bank and they are tuned to the most relevant harmonic frequency. The third harmonic can be attenuated by the delta connection of the TCR. The fixed capacitors (FC), and the thyristor controlled reactor may be considered essentially to consist of a variable reactor (controlled by delay angle $\alpha$ ) and a fixed capacitors, with an overall var demand versus var output characteristic as shown in figure No 4.

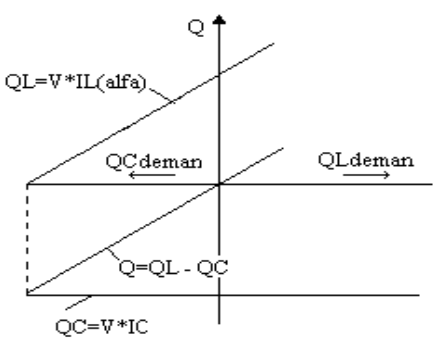

Fig. 4. Vars demand versus vars output characteristic

As seen, the constant capacitive var generation "QC" of the fixed capacitor is opposed by the variable var absorption "QL" of the thyristor-controlled reactor, to yield the total var output "Q" required. At the maximum capacitive var output, the thyristor-controlled reactor is off $\left(\alpha=180^{\circ}\right)$. To decrease the capacitive output, the current in the reactor is increase by decreasing firing angle $\alpha$. At zero var output, the capacitive and inductive current become equal and thus the capacitive and inductive vars cancel out. In the studied case the capacitive vars equal the maximum inductive vars that output the TCR.

\section{Voltage Stability}

The static var compensator (SVC) is frequently used to regulate the voltage at dynamic loads. But also, it is used to provide a voltage support inside of a power system when it takes place small gradual system changes such as natural increase in system load, or large sudden disturbance such as loss of a generating unit or a heavily loaded line[6]. These events can alter the pattern of the voltage waveform in such a manner that it can damage or lead to mal function of the protection devices. Generally, there are sufficient reserves and the systems settles to stable voltage level. However, it is possible, (because a combination of events and systems conditions), that the additional reactive power demands may lead to voltage collapse, causing a major breakdown of part or all system.

The SVC can improve and increase significantly the maximum power through the lines. This is achieved, if the SVC is operated an instant after of a disturbance providing the necessary flow of power. Therefore, if the approach of maximum transmitted power, is of voltages, it is possible to increase the power flow. In the 
studied case, it is seen that the transmitted power rise enough according to the used approach, keeping the voltage magnitude within the range of $0.8-1.2$ p.u..

\section{Power Systems}

The power system considerate in this study, is modeled by means of the ATP/EMTP program [4], [5]. It is a part of the interconnected power system of Venezuela, located in the southeast region of the country. It consists of four (4) generator bus, twelve (12) load bus, nine (9) power transformers, three (3) reactors and twenty three (23) transmission lines. All the elements were modeled using the ATP/EMTP models like : the sources type 59 for the generators, the saturable transformer for the three-phase transformers, piequivalent circuit for the transmission lines and uncoupled, lumped, series R-L-C branch for the loads. To turn on or to turn off the thyristors[1],[2],[6] a transient analysis control system (TACS) is used which it is an additional tool of the ATP/EMTP program.

\section{A. Simulation}

The simulations were carried out for the following contingencies:

a. Load increase in order to rise the power flow through the main transmission system.

b. Three-phase fault in the "Guri" bus after the load increase.

In the contingency "a" the load at "San Gerónimo" bus is increased, and the voltage profile will be different. Therefore, each time the load is increased it will be necessary to run a power flow analysis program to get the new voltage profile which it will be the new initial conditions for the fault calculations.

In the contingency " $b$ ", the three-phase short-circuit have a clearance time of three cycles. After this time interval the transmission line is out of operation, therefore the configuration of the system changes and the control system will be able to change the operation point of the SVC.

At the first step of the simulation, without the SVC and before the fault, the load was increased until the voltage level at the load buses, after the clearance of the fault at the bus called "Guri", will be near the specified limit of 1.2-0.8 p.u.. For this condition the maximum transmitted power through the "Malena-San Gerónimo" Overhead power lines was found.

At the second step a SVC was connected to "Malena" bus. A dynamic compensator of 400 Mvar capacitive supplies by the filters and the fixed capacitor allow to rise the maximum power through the lines between "Malena" and "San Gerónimo" buses for the three- phase fault about $48 \%$ while the voltage level was kept within the range of 1.2-0.8 p.u. The inductive rating of the compensator to fully compensate for the reactive power requirement at the "Malena" bus is 400Mvar. Hence a compensator of $-400,+400 \mathrm{Mvar}$ will meet the voltage requirement.

The total power flow measure at the power lines between "Malena"-"San Gerónimo" buses is calculated in p.u. of the thermal limit of the lines and they are shown in a tabulated and drawing way.

\section{B.Results}

In figure No 5 and in Table I are shown the results of the simulation without the dynamic compensator (SVC) and a three-phase fault located at "Guri" bus, where it can be seen that the maximum power flow through "Malena" - "San Gerónimo" overhead lines reach 2175.6 Mva per phase, keeping the level voltage within the specified range of 1.2-0.8 p.u.

Now, in figure No 6 and in Table I the simulations results with the 400 Mvar SVC operating at "Malena" bus and for the same kind of fault show that the transmitted power reach a new value of 3056.2 Mva as a maximum power flow as it is compare with the case given above while the voltage level are maintained in the specified range of 1.2-0.8 p.u

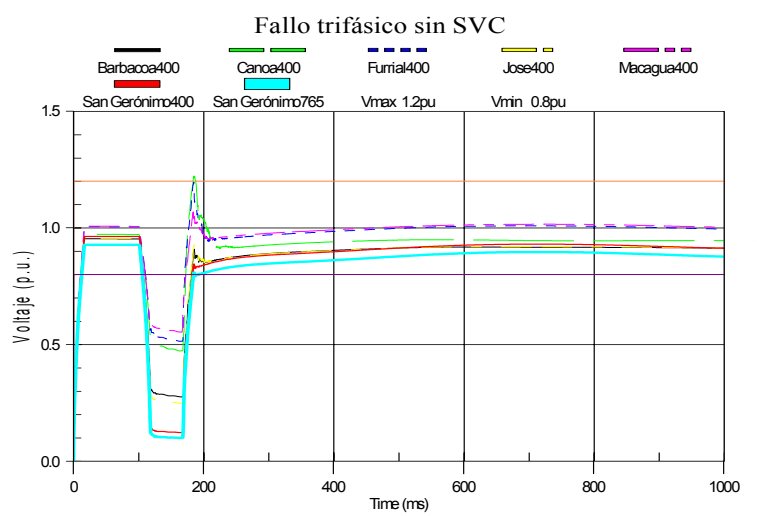

Fig. 5 Voltage levels at the system buses for three-phase fault without SVC

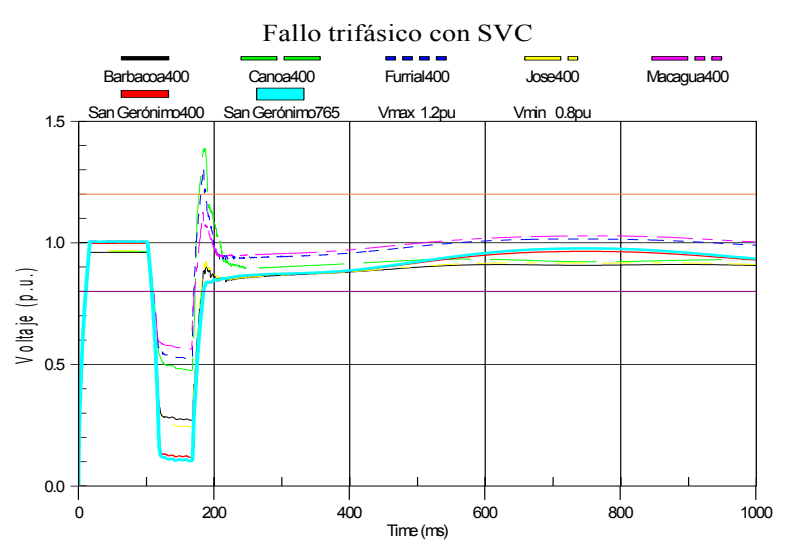

Fig. 6 Voltage levels at the system buses for three-phase fault with SVC 
Table I.-Power increased for three-phase fault

\begin{tabular}{|c|c|c|c|c|}
\hline & $\begin{array}{c}\text { Transmitted } \\
\text { Power } \\
(\mathrm{pu})\end{array}$ & $\begin{array}{c}\text { Maximum } \\
\text { Transmitter } \\
(\mathrm{MVA})\end{array}$ & $\begin{array}{c}\text { Power } \\
\text { Increment } \\
(\mathrm{MVA})\end{array}$ & $\begin{array}{c}\text { Power } \\
\text { Increment } \\
(\%)\end{array}$ \\
\hline $\begin{array}{c}\text { System } \\
\text { without } \\
\text { SVC }\end{array}$ & 0.42 & 2175.6 & - & - \\
\hline $\begin{array}{c}\text { System } \\
\text { with SVC } \\
(800)\end{array}$ & 0.62 & 3211.6 & 1036.0 & $\mathbf{4 7 . 6} \%$ \\
\hline $\begin{array}{c}\text { System } \\
\text { with SVC } \\
\text { (400) }\end{array}$ & 0.59 & 3056.2 & 880.6 & $\mathbf{4 0 . 3 5 \%}$ \\
\hline \multicolumn{4}{|c|}{ Thermal Capacity $=\mathrm{S}_{\mathrm{b}}=5180$ MVA (three lines) } \\
\hline
\end{tabular}

\section{Conclusions}

This work shows the application of the dynamic compensator (SVC) for increasing the power flow, under the thermal capacity, through an overhead transmission lines using a voltage stability criterion to achieve the propose target. This was fulfilled by a simulations carried out in the ATP/EMTP program of a model of the power system located in the southeast region of Venezuela, where exist important loads related with the oil industry using as a voltage criterion a specified range of 1.2-0.8 p.u. for the voltage variation.

As it can be observed in this work the power flow could be increased about $48 \%$ with the SVC respect the case without this device and it could be seen that the voltage levels was kept within the range of 1.2-0.8 p.u. when a three-phase short circuit occurred.

The results show that the optimum power for the SVC is about 400 MVA since a substantial increment of the SVC power (from 400 to $800 \mathrm{MVA}$ ) it does not produce any important increase of the maximum transmitted power. In order to calculate the SVC optimum power, a detailed analysis of costs should be done.

Additionally to the increment of the maximum transmitted power through the main power lines, the SVC offers other operative advantages that should be considered in the analysis of costs, since it contributes to improve substantially: the transient system stability, the quality standards of the electric service at low voltage level, the unbalances of the system and the voltage profiles in the steady and transient state.

The methodology used was simple and show step by step all the adjustments and calculations necessary for a satisfactory operation of the system. For last, it is important to stand up the practical and simple handling of the models of the ATP/EMTP to implement a very complex study.

\section{References}

[1]. Miller T.J.E., "Reactive Power Control in Electric Systems", Wiley\&Sons, New York, (1982).

[2]. Hingorani Narain y Gyugyi, Lazlo. "Understanding FACTS: concepts and technology of flexible AC transmission systems", IEEE Press, New York (2000).

[3]. Gyugyi, L, Otto, R. y Putman, T.H. "Principles and Applications of Static Thyristor-Controlled Shunt Compensator", Trans IEEE Power Appar Syst 97, pp 1935-1945, September/October, 1978.

[4]. Van Dommelen Daniel," Alternative Transients Programs Rule Book", Leuven EMTP Center (LEC), Belgium, 1987.

[5]. Dommel Hermann, "Electromagnetic Transients Program reference manual (EMTP Theory Book)", Bonneville Power Administration, Portland, 1986.

[6]. Kundur P., Power Systems Stability and Control, McGraw-Hill, New York (1994). 